\title{
Corrigendum
}

\section{Corrigendum to "Functional and Spatial Design of Emergency Departments Using Quality Function Deployment"}

\author{
Yassin Abdelsamad (D), Muhammad Rushdi (i), and Bassel Tawfik \\ Department of Biomedical Engineering and Systems, Faculty of Engineering, Cairo University, Giza 12613, Egypt \\ Correspondence should be addressed to Yassin Abdelsamad; yassin_bme@yahoo.com \\ Received 18 June 2019; Accepted 20 June 2019; Published 17 July 2019 \\ Copyright (c) 2019 Yassin Abdelsamad et al. This is an open access article distributed under the Creative Commons Attribution \\ License, which permits unrestricted use, distribution, and reproduction in any medium, provided the original work is \\ properly cited.
}

In the article titled "Functional and Spatial Design of Emergency Departments Using Quality Function Deployment" [1], there was an error in equation (4). Although this error does not affect the results or the conclusions, the double indexes $i, j$ and $n, m$ might be confusing for the reader. Therefore, equation (4) should be corrected as follows.

For the final step of HoQ, the technical target matrix contains the technical priority $\mathrm{TP}$ and the relative weight RW of each functional unit. The technical priority is calculated as

$$
\mathrm{TP}_{j}=\sum_{i=1}^{n} C_{i, j} * \mathrm{RW}_{i}
$$

where $C_{i, j}$ is the correlation value between requirement $i$ and specification $j, \mathrm{RW}_{i}$ is the relative weight, and $n$ represents the number of SRs.

\section{References}

[1] Y. Abdelsamad, M. Rushdi, and B. Tawfik, "Functional and spatial design of emergency departments using quality function deployment," Journal of Healthcare Engineering, vol. 2018, Article ID 9281396, 7 pages, 2018. 


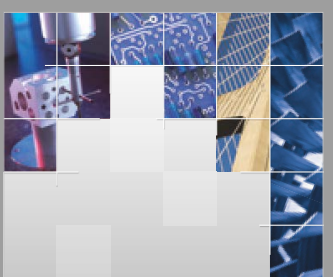

\section{Enfincering}
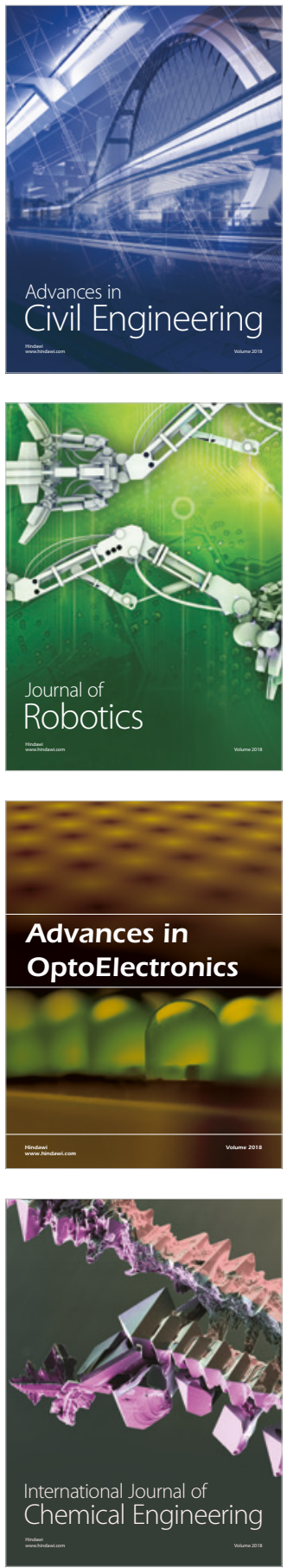

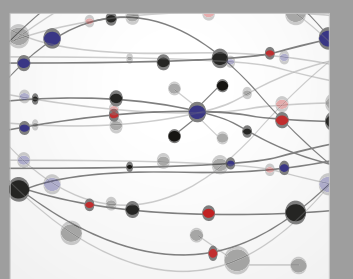

\section{Rotating \\ Machinery}

The Scientific World Journal

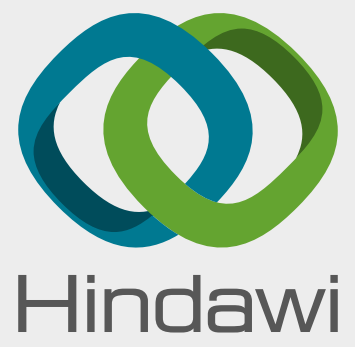

Submit your manuscripts at

www.hindawi.com
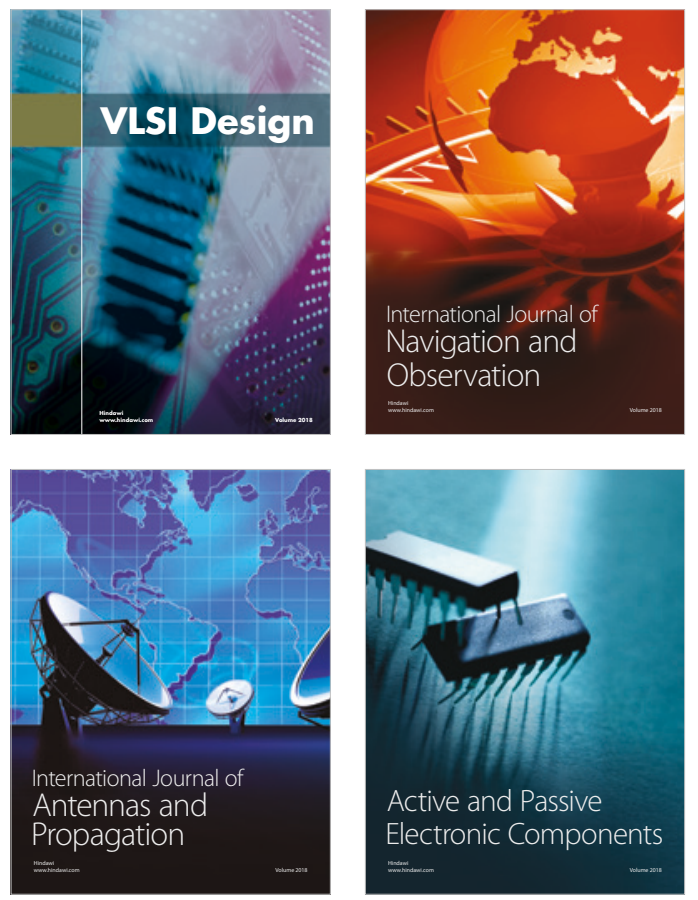
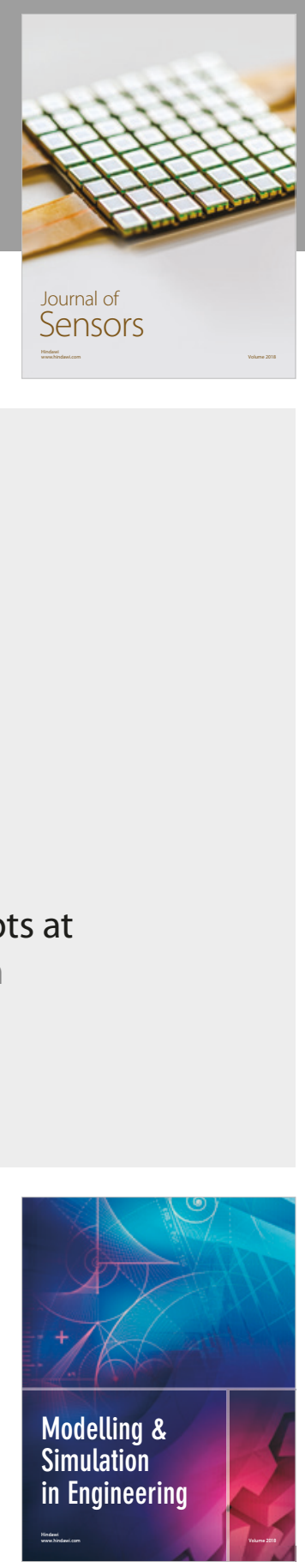

\section{Advances \\ Multimedia}
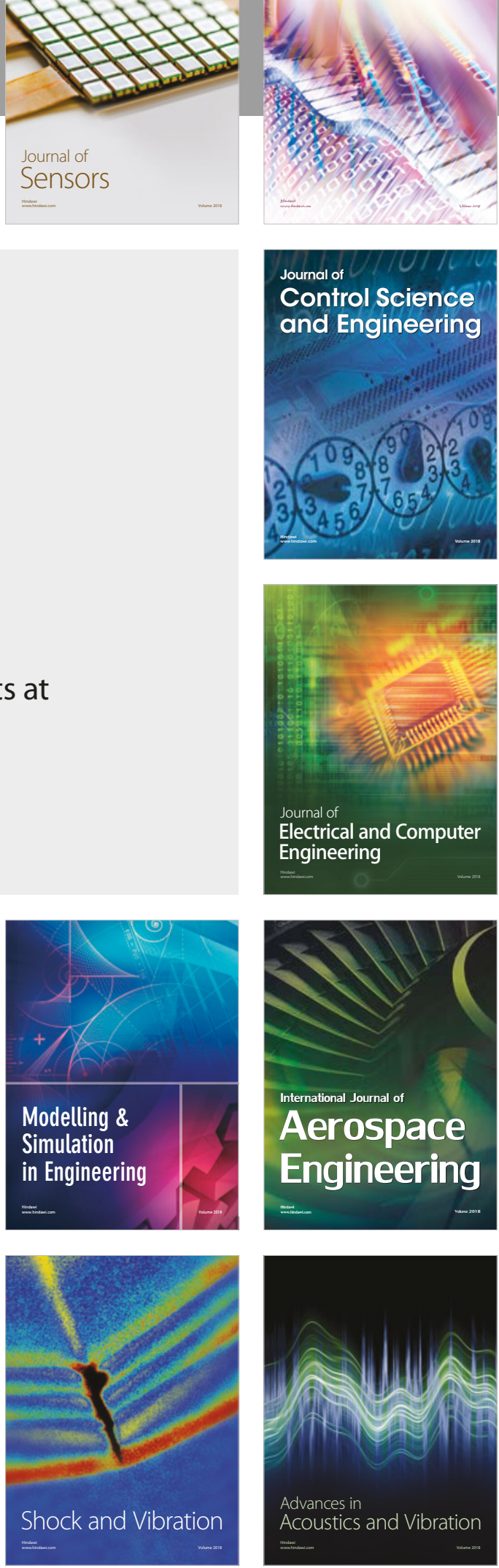